\title{
Optically-guided instrument for transapical beating-heart delivery of artificial mitral chordae tendineae
}

\author{
Zurab Machaidze, MD, ${ }^{\mathrm{a}}$ Margherita Mencattelli, PhD, ${ }^{\mathrm{a}}$ Gustavo Arnal, BS, ${ }^{\mathrm{a}}$ Karl Price, MS, ${ }^{\mathrm{a}}$ \\ Fei-Yi Wu, MD, ${ }^{\mathrm{b}}$ Viktoria Weixler, MD, ${ }^{\mathrm{a}}$ David W. Brown, MD,${ }^{\mathrm{c}}$ John E. Mayer, Jr, MD, ${ }^{\mathrm{a}}$ and \\ Pierre E. Dupont, $\mathrm{PhD}^{\mathrm{a}}$
}

\section{ABSTRACT}

Objective: We sought to develop an instrument that would enable the delivery of artificial chordae tendineae (ACT) using optical visualization of the leaflet inside the beating heart.

\begin{abstract}
Methods: A delivery instrument was developed together with an ACT anchor system. The instrument incorporates an optically clear silicone grasping surface in which are embedded a camera and LED for direct leaflet visualization during localization, grasping, and chordal delivery. ACTs, comprised of T-shaped anchors and an expanded polytetrafluoroethylene chordae, were fabricated to enable testing in a porcine model. Ex vivo experiments were used to measure the anchor tear-out force from the mitral leaflets. In vivo experiments were performed in which the mitral leaflets were accessed transapically using only optical guidance and ACTs were deployed in the posterior and anterior leaflets (P2 and A2 segments).
\end{abstract}

Results: In 5 porcine ex vivo experiments, the mean force required to tear the anchors from the leaflets was $3.8 \pm 1.2 \mathrm{~N}$. In 5 porcine in vivo nonsurvival procedures, 14 ACTs were successfully placed in the leaflets (9 in P2 and 5 in A2). ACT implantation took an average of $3.22 \pm 0.83$ minutes from entry to exit through the apex.

Conclusions: Optical visualization of the mitral leaflet during chordal placement is feasible and provides direct feedback to the operator throughout the deployment sequence. This enables visual confirmation of the targeted leaflet location, distance from the free edge, and successful deployment of the chordal anchor. Further studies are needed to refine and assess the device for clinical use. (J Thorac Cardiovasc Surg 2019;158:1332-40)

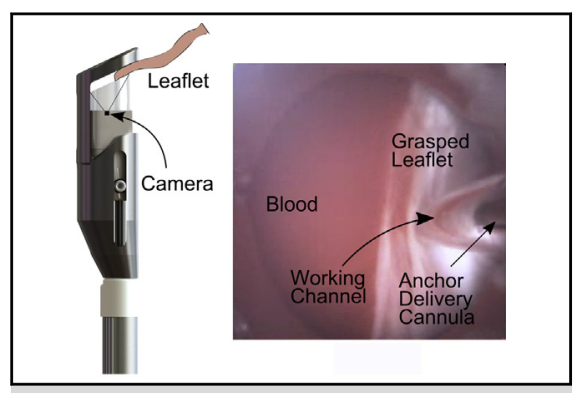

Instrument for artificial chordae implantation provides tip-camera view of leaflet grasping and anchor delivery.

\section{Central Message}

We present an innovative instrument for off-pump neochordae implantation incorporating submillimeter-resolution optical imaging to guide anchor positioning and to validate successful deployment.

\section{Perspective}

This work shows how streaming optical video can be used to guide leaflet manipulation during off-pump neochordae implantation. The high-resolution images of instrument-tissue contact area provided by this technology fill an important gap in the capabilities of the current off-pump imaging modalities, echocardiography and fluoroscopy, and so might prove clinically useful to many valve repair tasks.

See Commentaries on pages 1341 and 1343.
From the Departments of a Cardiovascular Surgery and 'Cardiology, Boston's Children's Hospital, Boston, Mass; and ${ }^{\mathrm{b}}$ Division of Cardiovascular Surgery, Taipei Veterans General Hospital, Taipei, Taiwan.

This work was funded by the National Institutes of Health under grant R01HL124020.

Drs Machaidze and Mencattelli contributed equally to these experiments and this report.

Received for publication Nov 13, 2018; revisions received Jan 30, 2019; accepted for publication Feb 10, 2019; available ahead of print April 17, 2019.

Address for reprints: Pierre E. Dupont, PhD, Boston Children's Hospital, 330 Longwood Ave, Enders Building 350, Boston, MA 02115 (E-mail: pierre.dupont@ childrens.harvard.edu).

$0022-5223 / \$ 36.00$

Copyright (c) 2019 by The American Association for Thoracic Surgery

https://doi.org/10.1016/j.jtcvs.2019.02.120
Mitral valve prolapse of the anterior and/or posterior leaflet is the most common cause of mitral regurgitation with a prevalence of $2 \%$ to $3 \% .{ }^{1}$ For many years, arrested-heart mitral repair has been the "gold standard" to correct mitral

- Scanning this QR code will take you to the article title page to access supplementary information.

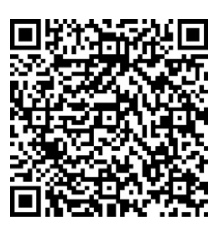




\section{Abbreviations and Acronyms}

$\mathrm{ACT}=$ artificial chordae tendineae

ePTFE $=$ expanded polytetrafluoroethylene

valve prolapse. ${ }^{2,3}$ The introduction of minimally invasive techniques, however, has opened up new avenues for further development and expansion of this approach. ${ }^{4-11}$ Current clinical minimally invasive techniques deliver artificial chordae tendineae (ACT) using transesophageal echocardiography as the primary imaging modality to guide chordal placement. Although endoscopic techniques have shown promise for beating-heart interventions, ${ }^{12-18}$ optically guided off-pump tissue grasping and mitral valve repair have not been previously investigated. In this report, we explore the use of endoscopically-guided mitral leaflet segment localization, grasping, and neochordal implantation. This approach enables directly visualized chordal placement virtually anywhere on the valve.

\section{METHODS}

\section{Instrument Design}

The device (Figure 1) incorporates a soft, optically clear silicone grasping finger with an embedded $1-\mathrm{mm}^{2} 256 \times 256$ pixel chip-based camera and a $1.6-\mathrm{mm}^{2}$ light-emitting diode for illumination. When the fingers are completely closed, the optical finger is slightly extended (Figure 1, A) enabling visualization of whatever is contacting the instrument tip during insertion into the heart and navigation to the valve. The camera provides a full view of the optical finger surface, which is displayed for the clinician and reveals if the finger is in contact with blood or tissue (Figure 1, $A$ ). The opposing finger is comprised of a ring encircling the optical finger that is fixed with respect to the instrument shaft. The optical finger slides relative to the ring-shaped finger for leaflet grasping (Figure 1,B).

The design is scalable in diameter and limited only by the camera and LED dimensions. The field of view is determined by the diameter of the optical window. As constructed, the optical finger is $8 \mathrm{~mm}$ in diameter and the opposing ring-shaped finger is $10.5 \mathrm{~mm}$ diameter. A 2-mm diameter channel is included in the optical finger for chordal delivery (Figure 1, A). The channel walls are transparent allowing visualization of chordal delivery (Figure 1, B).

The ACT delivery system consists of a stainless-steel cylindrical anchor (1.25-mm diameter) attached to an expanded polytetrafluoroethylene (ePTFE) chord (Figure 2, A), which slides over a stylet, which extends through a delivery cannula (Figure $2, B$ ). The instrument shaft (6-mm diameter) and the ACT delivery cannula have integrated Luer-lock male fittings for saline infusion to prevent air bubbles from entering the bloodstream, to avoid blood backflow from the ventricle and to enable ACT delivery inside the channel.

After insertion into the apex of the left ventricle, the instrument is navigated to the mitral valve using ultrasound guidance and is oriented on the basis of the targeted area of the leaflet. During navigation to the valve, the fingers are closed and the imaging finger displays only blood until contact with the valve occurs (Figure $3, A$ ). The optical finger provides an $8-\mathrm{mm}$ diameter circular field of view with a pixel size of approximately $31 \times 31 \mu \mathrm{m}$. When the targeted leaflet segment is reached, the open

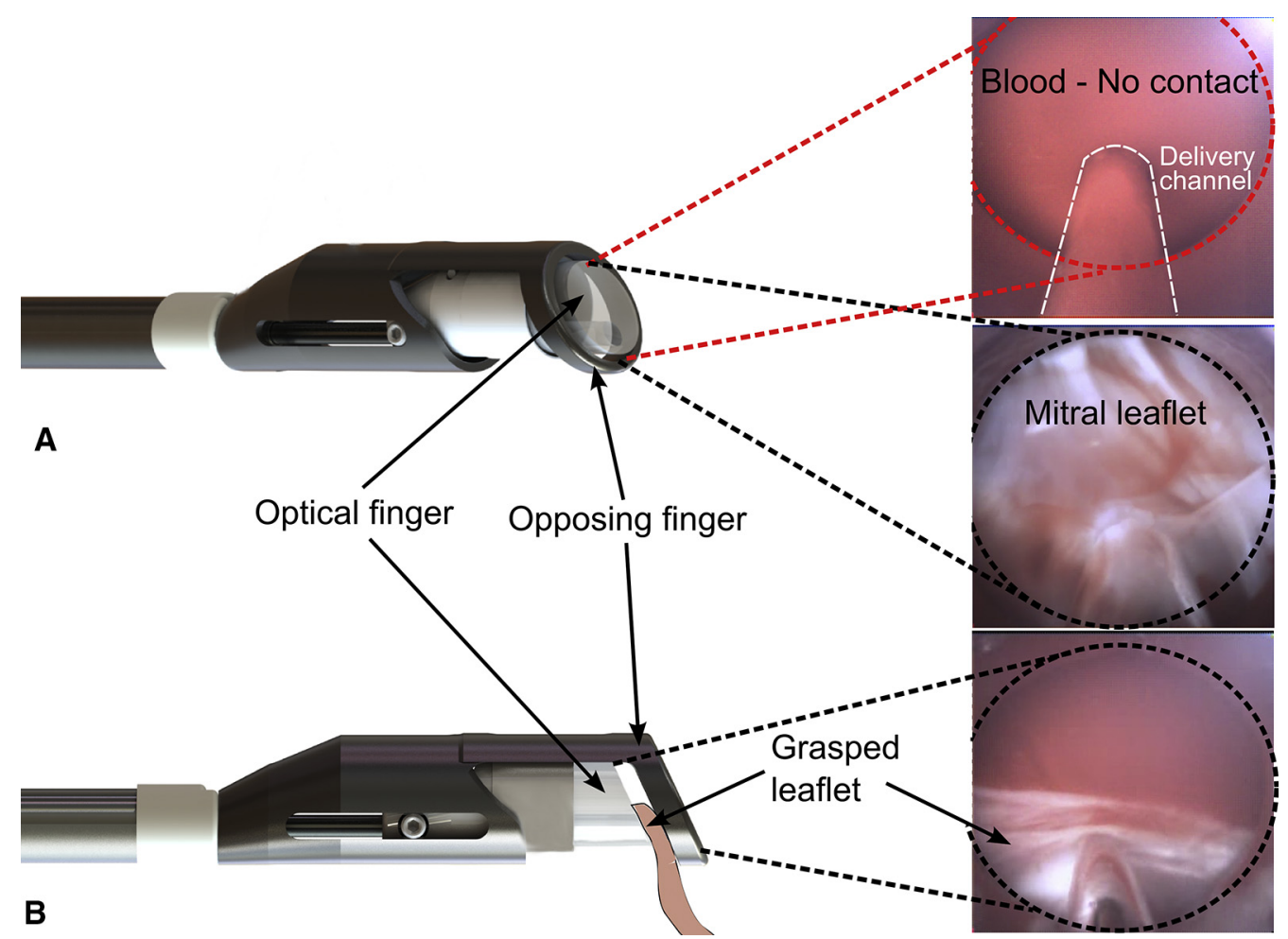

FIGURE 1. Optically-guided artificial chordae delivery instrument. Video camera and LED embedded in optical finger provide clinician with real-time view of optical finger surface. Delivery channel running through optical finger can be seen in images. A, With fingers closed during instrument navigation, the operator can view what is touching the instrument tip (eg, blood or leaflet tissue as shown on the right). B, Optical finger slides with respect to ring-shaped opposing finger to enable leaflet grasping. Leaflet image from optical finger shows tissue quality and distance from delivery channel to leaflet free edge. Artificial chordae tendineae delivery system can be seen inside delivery channel. 


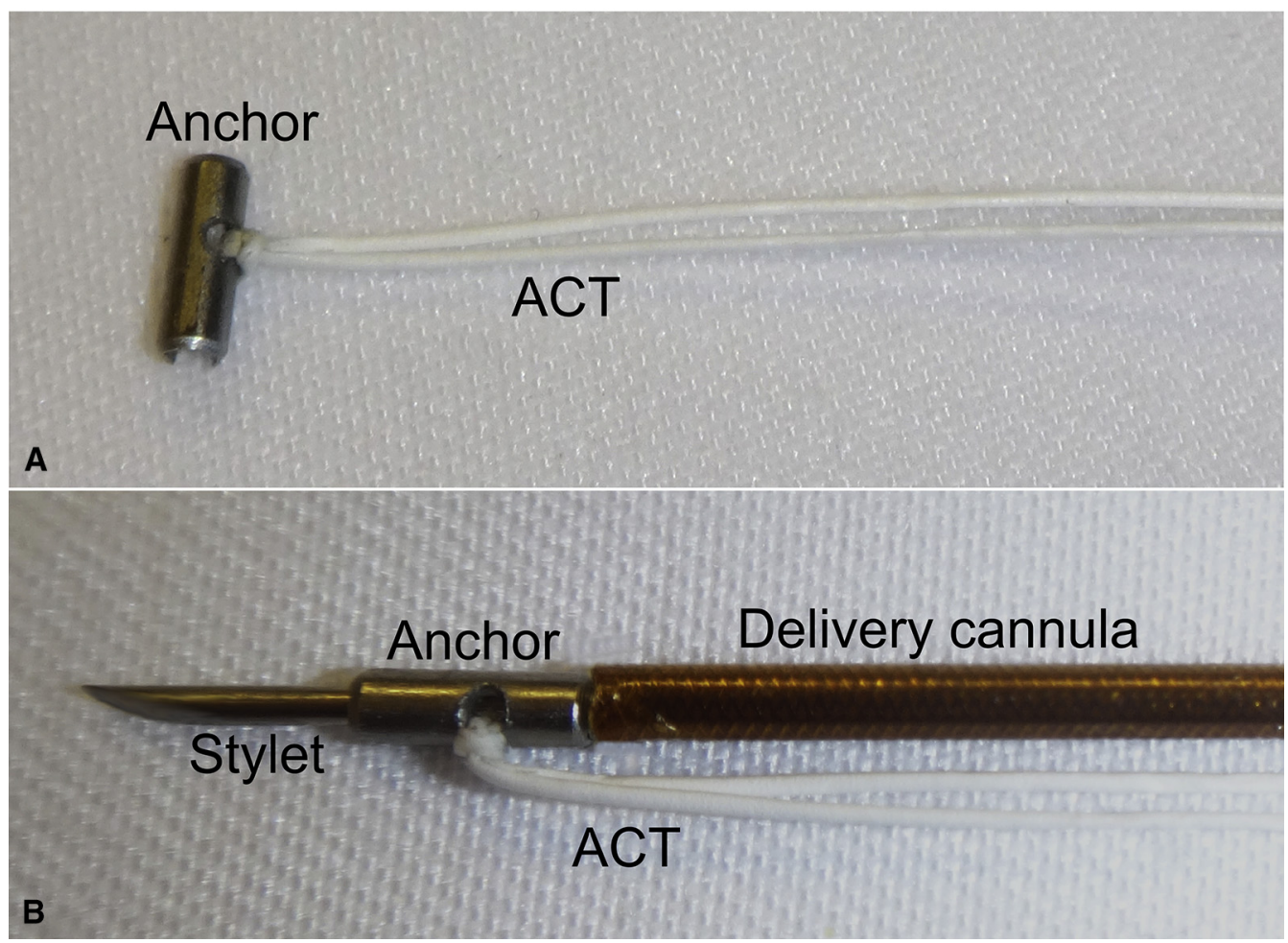

FIGURE 2. Artificial chordae tendineae (ACT) delivery system. A, Cylindrical anchor attached to expanded polytetrafluoroethylene chordae. B, Anchor slides over stylet and rests on delivery cannula. Assembled system is inserted through delivery channel of instrument.

circular finger is extended to allow the leaflet edge to enter into the grasping zone between the fingers. The instrument position is then adjusted to place the delivery channel at the desired location on the leaflet. The sliding finger is then closed and the grasped location of the delivery channel is confirmed visually (Figure $3, B$ ). If necessary, this process is repeated until a satisfactory location is visually confirmed. The anchor delivery system is then advanced through the optical finger such that the stylet pierces the leaflet (Figure 3,C) and the entirety of the anchor is visually observed to pass through to the atrial side of the leaflet. The stylet is first withdrawn from the delivery cannula to release the anchor. The delivery cannula is then withdrawn through the optical finger leaving the anchor on the atrial side of the leaflet (Figure 3,D). The chordae, still running through the delivery channel, is then gently pulled to place it in a T configuration flush to the leaflet and the fingers are then fully opened to release the leaflet and the instrument is withdrawn over the ACT from the heart (Figure 3,E). The ACT can then be adjusted to the appropriate length using ultrasound guidance (Figure 3,F).

\section{Ex Vivo Experiments}

To evaluate the force required to tear the proposed anchors out of mitral leaflets, ex vivo experiments were carried out in fresh porcine hearts $(\mathrm{n}=5$; approximately $80-\mathrm{kg}$ pigs) acquired from a local abattoir. The left ventricle and atrium were opened to expose the mitral valve and the heart was fixed in place. The delivery instrument was used to sequentially place ACTs in each of the 3 segments of the anterior and posterior leaflets. The end of each ACT was attached to a digital force sensor, which automatically records maximum force (resolution $\pm 0.01 \mathrm{~N}$ ). The tension on the chordae was slowly increased until the anchor tore out of the leaflet and the maximum force was recorded. A total of 30 anchors were deployed and tested.

\section{In Vivo Experiments}

Nonsurvival surgical experiments in Yorkshire swine were approved by the Institutional Animal Care and Use Committee of Boston Children's Hospital (17-05-3468R*) on February 19, 2018. While the ex vivo experiments evaluated the ACTs, the goal of the in vivo experiments was to assess the optically guided delivery instrument.

\section{Surgical Procedure}

Swine $(\mathrm{n}=5 ; 80-85 \mathrm{~kg})$ were obtained from a local breeder (Parsons Farm, Westhampton, Mass) for surgical experiments. Animals were premedicated with atropine $(0.04 \mathrm{mg} / \mathrm{kg}$, intramuscular) followed by tiletamine and zolazepam for injection $(4.4 \mathrm{mg} / \mathrm{kg})$ and xylazine $(2.2 \mathrm{mg} /$ $\mathrm{kg}$ intramuscular) and after endotracheal intubation they were given isoflurane $(1.5 \%-2 \%)$ or desflurane $(8 \%-12 \%)$ general anesthesia. After accessing the chest via median sternotomy and pericardiotomy, heparin was administered intravenously to achieve an activated clotting time greater than 350 seconds. Two pledgeted purse-string sutures were placed on the apex and the instrument was inserted through a transapical access.

The instrument, preloaded with an ACT, was inserted through the apex and navigated to the mitral valve. Although ultrasound guidance would normally be used to reach the valve, we found that we could navigate to the valve "blindly" and that, when in contact, the optical image stream was sufficient to position the instrument with respect to the valve. The ACT was delivered as described previously and the instrument was withdrawn from the heart through the apical incision (Figure 3; Video 1). Total delivery time from insertion to removal of the instrument was recorded. ACTs were placed in the P2 and A2 segments. In 2 animals, multiple anchors were placed within a segment. 

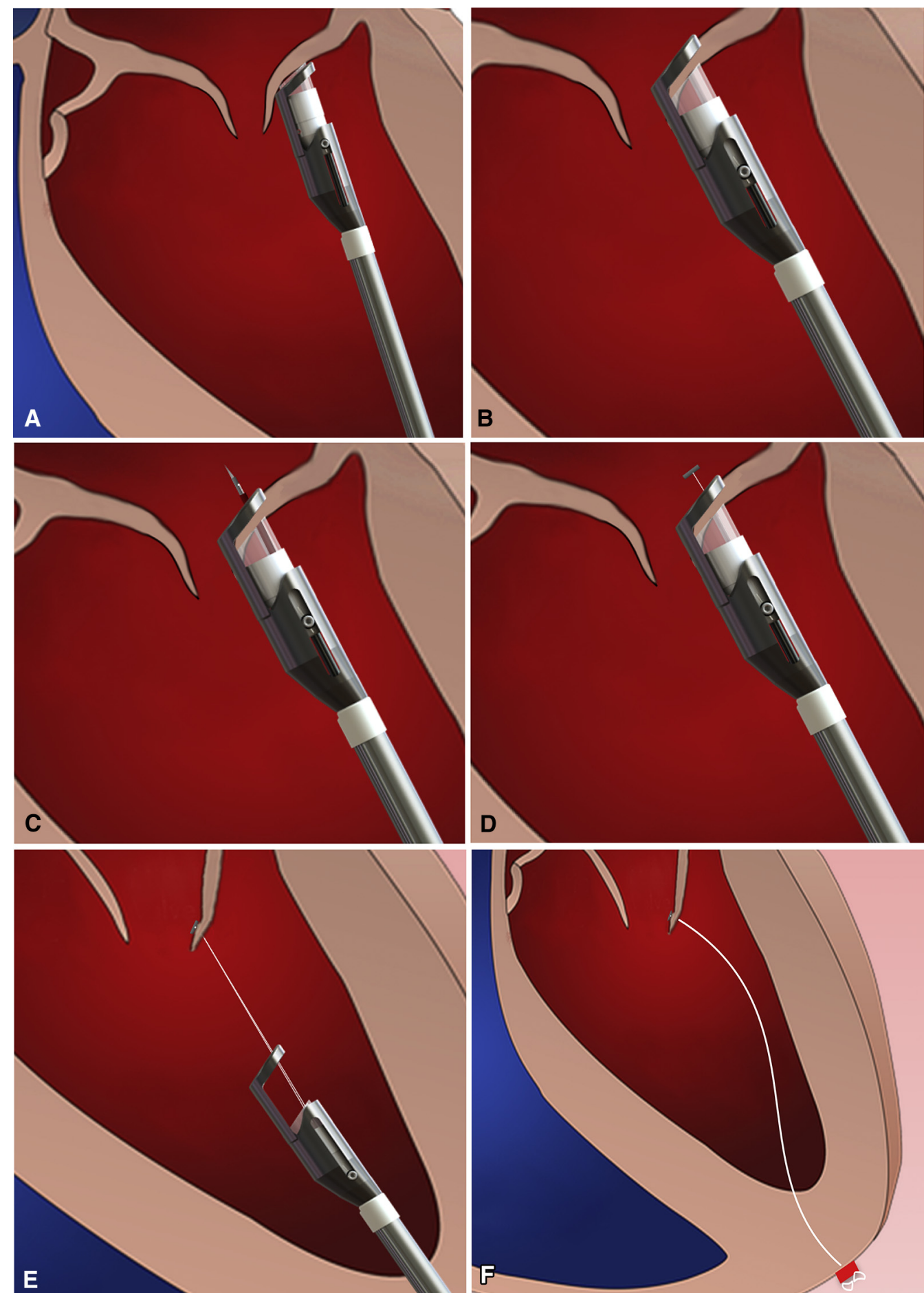

FIGURE 3. Artificial chordae tendineae (ACT) delivery to the mitral valve. A, Instrument is advanced to the valve with fingers closed. B, Leaflet is grasped. $\mathrm{C}$, ACT delivery system is extended through delivery channel so that stylet pierces leaflet. D, Stylet and delivery cannula are removed leaving anchor on atrial side of leaflet. E, Instrument is withdrawn through apex. F, ACT length is adjusted using ultrasound guidance and tied off outside the apex.

\section{Intraoperative Echocardiography}

Intraoperative 2-dimensional transepicardial echocardiography was used to assess ACT placement. Because the animal model did not include the creation of prolapse, it was not possible to adjust chordae length to correct prolapse. Instead, to ensure that the chordae was firmly attached to the leaflet, we shortened it to produce leaflet tethering and observed valve function using ultrasound over a period of approximately 10 cycles. 


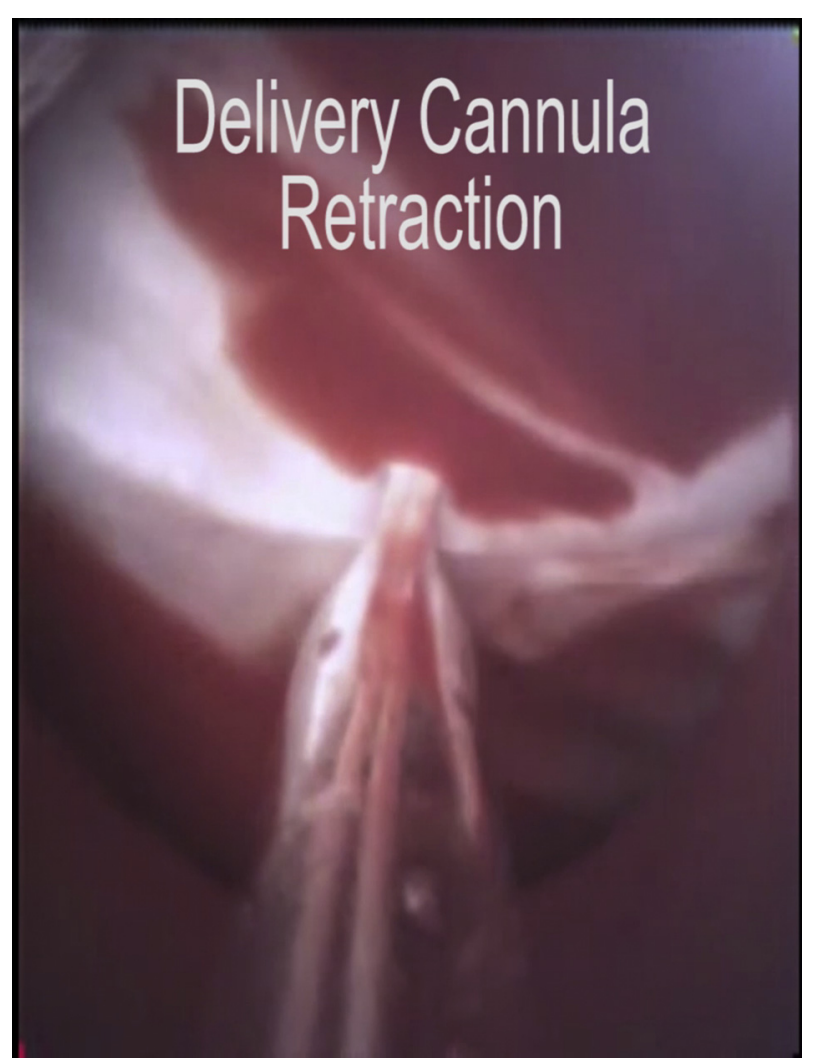

VIDEO 1. This video shows the optical finger view of artificial chordae tendineae implantation during an in vivo experiment. Video available at: https://www.jtcvs.org/article/S0022-5223(19)30671-3/fulltext.

\section{Postoperative Assessment}

After each experiment, the hearts were excised and the left ventricle and atrium were opened. ACT anchors and leaflets were inspected and photographed.

\section{RESULTS}

\section{Ex Vivo Experiments}

In 5 fresh porcine hearts, the mean force required to tear the ACT anchors out of the anterior mitral leaflet was $3.9 \pm 1.2 \mathrm{~N}$. For the posterior leaflet, the mean force was $3.7 \pm 1.1 \mathrm{~N}$. The mean forces were highest for the $\mathrm{P} 2$ and A2 segments, at $4.5 \pm 0.9 \mathrm{~N}$ and $4.9 \pm 1.0 \mathrm{~N}$, respectively.

\section{In Vivo Experiments}

Fourteen attempts were made to deliver anchors to the $\mathrm{P} 2$ and A2 mitral segments (9 in P2, 5 in A2). In all cases, the anchors were successfully delivered and in all but 1 case, the anchors were placed in the desired segment. In the remaining case, which occurred during the learning curve of the first several implantations, the anchor was placed in the annulus instead of P2. ACT delivery time (apex-toapex) averaged $3.22 \pm 0.83$ minutes.

The reported experiments were the first conducted by the operator (Z.M.) with the instrument and include his learning curve. As the experiments progressed, the operator became proficient at using the contact imaging to deploy anchors at precise distances from the free edge (Figure 4, $A-C$ ). During leaflet grasping, it was possible to visualize the opposing leaflet because of the design of the grasping finger as an open ring (Figure 4, $D-G$ ).

When delivering multiple anchors to a leaflet segment, optical imaging enabled visualization of previously deployed chordae and precise relative positioning with respect to them (Figure 5, A). It was also possible to visualize anchor delivery to determine if an anchor had been deployed correctly (Figure 5, $B$ and $C$ ). The anchors and chordae could be visualized on epicardial echo (Video 2) and changes in valve function could be observed by adjusting chordae length using ultrasound guidance (Figure 6).

It was found to be important to keep the ACT under light tension during removal of the device to prevent entanglement of the chordae with the instrument. With a 14-inch long instrument, however, the length of ePTFE suture used in the experiments (18 inches) was not sufficiently long to manually maintain tension during the entire instrument removal process. This ACT design problem led to chordal entanglement and anchor dislodgement after successful placement on 4 occasions and loss of the ePTFE chordae into the ventricle after anchor delivery on 2 occasions. These problems can be corrected simply through the use of a longer suture.

\section{Postoperative Evaluation}

At the completion of each in vivo experiment, the heart was excised and opened to evaluate anchor placement (Figure 7). Except for the 1 anchor found in the annulus, all were positioned in the desired segment. For anchors that had been dislodged because of entanglement, the leaflet puncture location was verified to correspond to the intended delivery position. No leaflet damage due to grasping was observed. To deploy the anchor through the leaflet, the needle of the ACT delivery system creates a hole in the leaflet. In some instances, minor bruising was observed around the leaflet puncture hole.

\section{DISCUSSION}

The delivery of ACTs using optical guidance alone was performed reliably with delivery times (3.22 \pm 0.83 minutes) comparable to those reported for instruments guided using ultrasound. ${ }^{4,5}$ For example, Seeburger and colleagues ${ }^{5}$ reported an average implantation time of $3.83 \pm 1.98$ minutes for a surgeon with neochordal implantation experience equivalent to what is reported in this article. The direct high-resolution optical imaging provided by the proposed instrument enabled precise chordae positioning on the leaflets and also provided a means to assess the thickness and quality of the leaflet tissue before neochordal deployment. Direct imaging also enabled 
verification of successful anchor placement before release of the leaflet.

The ACTs used in these experiments were comprised of ePTFE suture, the standard material used in chordal replacement, combined with novel "T-bar" anchors. Ex vivo experiments showed that the mechanical forces needed to tear these anchors from fresh porcine leaflet tissue significantly exceeds the physiological forces $(<0.5 \mathrm{~N})$ measured in ACTs ${ }^{19}$ and native chordae. ${ }^{20}$ Although this anchor design is promising, it is noted that the optically guided delivery instrument can be adapted to deploy any type of anchor and artificial chordae.

The ACT delivery experiments reported herein are the first to investigate optically guided off-pump tissue grasping and leaflet manipulation. Previous work using off-pump optical guidance has shown its efficacy in
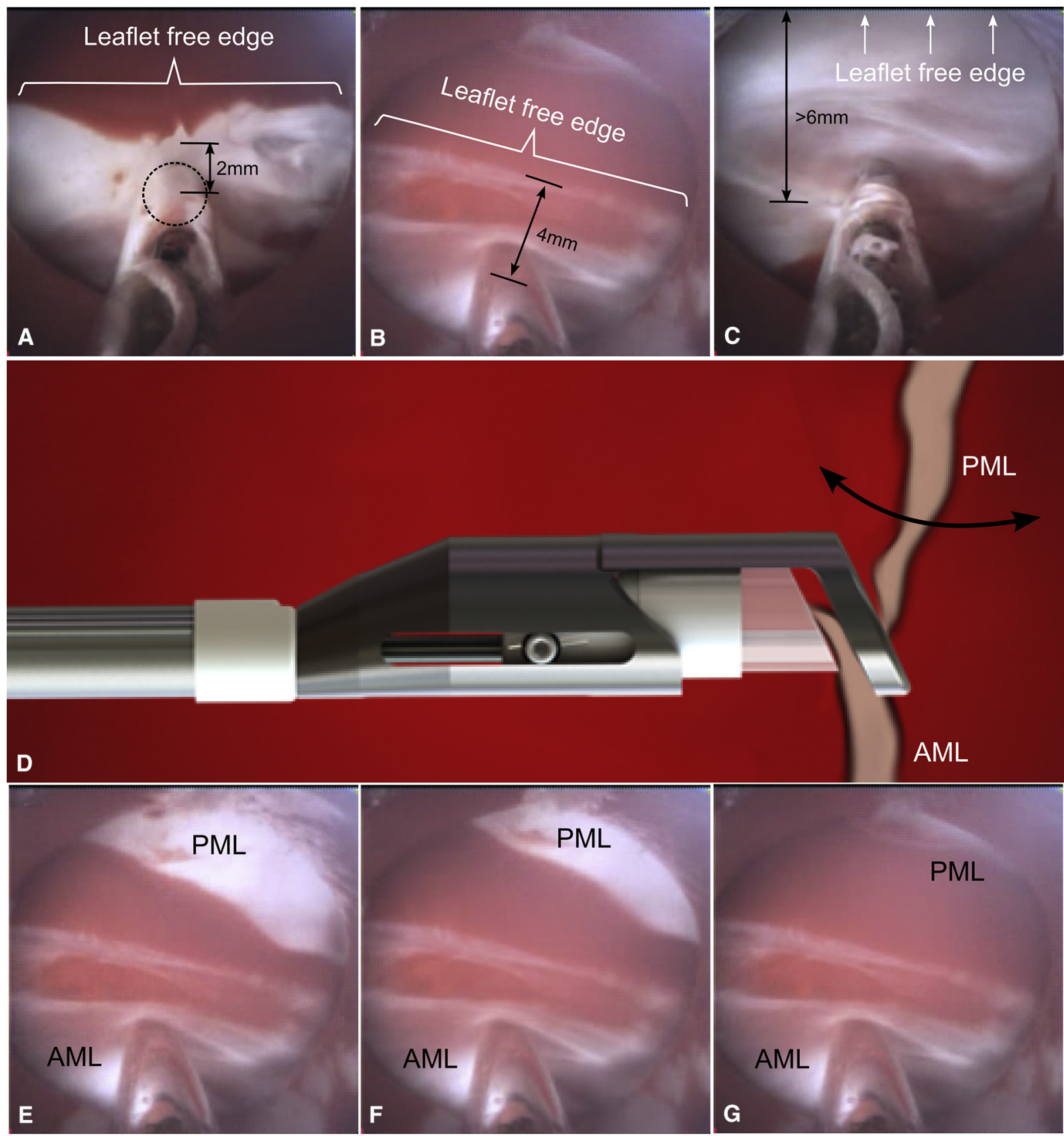

FIGURE 4. Leaflet imaging during grasping. A, Grasp positioning delivery channel $2 \mathrm{~mm}$ from leaflet free edge. B, Delivery channel is positioned $4 \mathrm{~mm}$ from free edge. C, Delivery channel is positioned over $6 \mathrm{~mm}$ from free edge. D, While anterior mitral leaflet $(A M L)$ is grasped, posterior mitral leaflet $(P M L)$ beats against optical finger. E through G, Three images over cardiac cycle corresponding to grasp of AML while PML beats on the optical finger. 

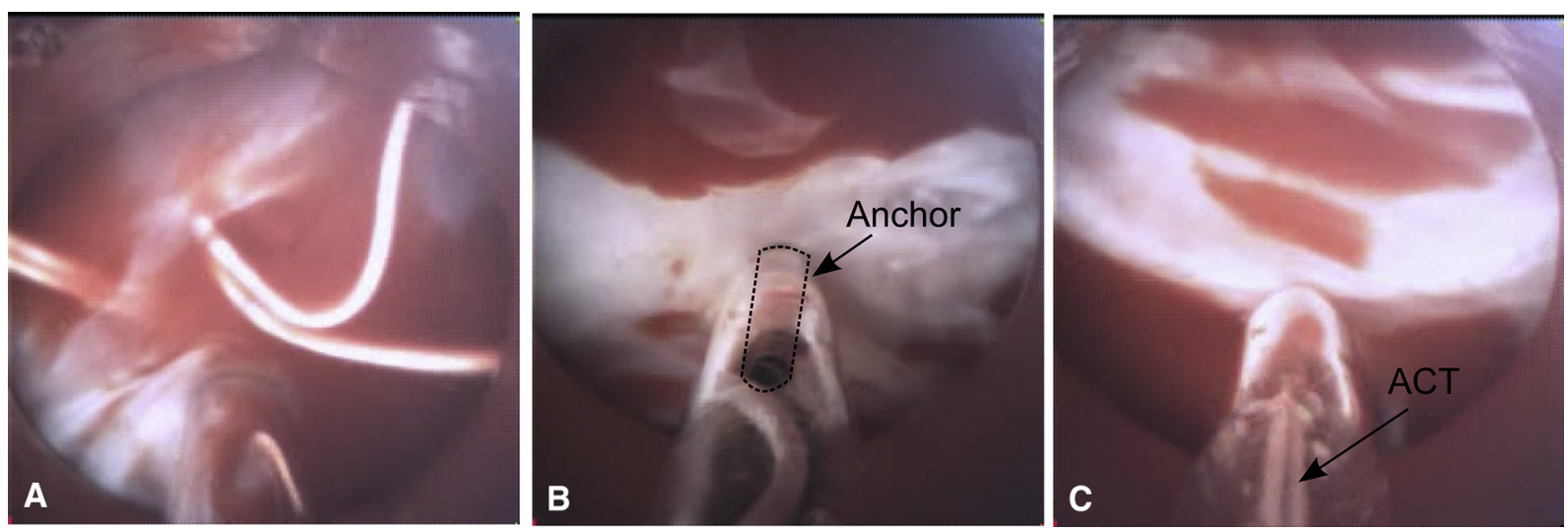

FIGURE 5. Image-based validation of anchor placement. A, Imaging previously placed chordae for verification or for implanting additional chordae. B and C, Verifying if an anchor has been successfully delivered. B, Unsuccessful delivery—anchor can be seen in delivery channel. C, Delivery success—artificial chordae tendineae $(A C T)$ can be seen passing through leaflet.

positioning the tip of the imaging instrument on intracardiac tissue to perform diagnostics ${ }^{12,13,16}$ or to deploy anchors, ${ }^{14}$ tools, ${ }^{17}$ and devices ${ }^{18}$ directly onto or into the tissue, but has not considered tissue grasping or leaflet manipulation.

In the only other work using optical guidance for leaflet manipulation, an innovative approach was used to continuously flush the ventricle with clear fluid for visualization. ${ }^{15}$ This technique was used to show clip application to the

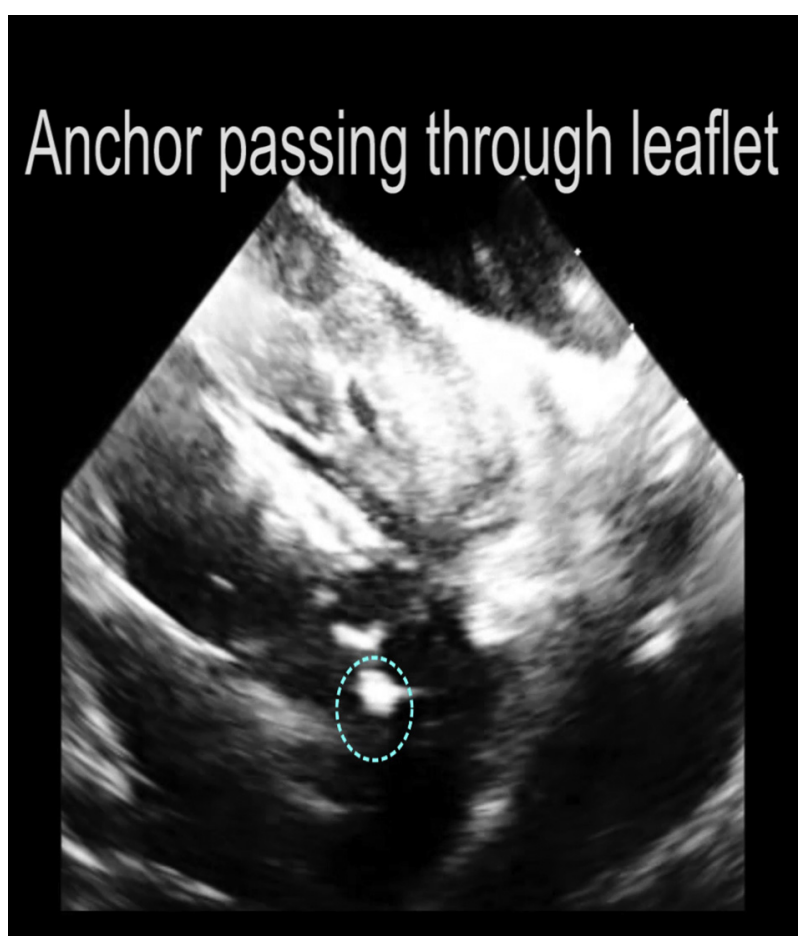

VIDEO 2. This video shows ultrasound imaging of the instrument during implantation of an artificial chordae tendineae in the anterior leaflet. Video available at: https://www.jtcvs.org/article/S0022-5223(19)30671-3/ fulltext. mitral and tricuspid valves. Although the heart is beating with this technique, it must be performed on-pump.

The key advantage of optical imaging is that it can reliably provide high-resolution images of the instrument-tissue contact area independent of the location and orientation of the instrument inside the heart. In contrast, current clinical devices for deploying artificial chordae $e^{4-9}$ and clips ${ }^{10,11}$ primarily rely on ultrasound imaging, which cannot reliably produce spatially accurate images at the instrument-tissue interface. This inaccuracy is due to the artifacts arising from the substantial difference in acoustic impedance between tissue and instrument materials. ${ }^{21,22}$ Furthermore, ultrasound image resolution depends on the quality of the acoustic window, which can vary from patient to patient and by location inside the heart. This variability can potentially affect the reliability and reproducibility of image-guided device positioning.

The next step in the development of this technology for ACT implantation is to modify the instrument design so as to minimize the diameter of the hole required for insertion through the cardiac apex. Such a design would reduce in diameter for passing through the apex and then expand when inside the ventricle to provide the desired field of view. Because the camera and LED are 1-mm scale, very compact designs are possible.

Beyond transapical ACT implantation, an expanding design could be used for transcatheter procedures in which precise visualization of catheter-tissue contact is important to optimizing the deployment of a broad range of off-pump valve repair and replacement technologies. For example, the placement of clips to reproduce the Alfieri stitch ${ }^{10,11}$ requires simultaneous visualization of both leaflets-a capability that is shown in Figure 4, $E$ through $G$. As a second example, future systems to deliver ACTs percutaneously will potentially attach the chordae to the papillary muscles. Optical imaging can provide the same high-resolution images of the papillary muscles as 

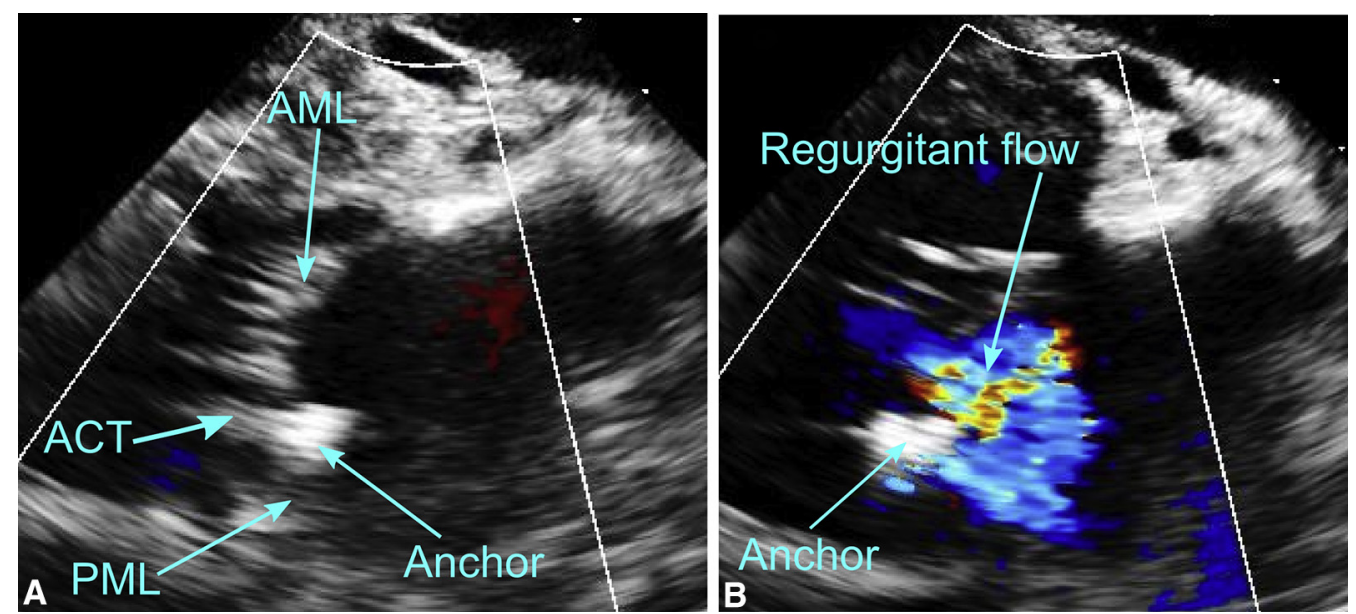

FIGURE 6. Ultrasound imaging after artificial chordae tendineae (ACT) delivery. A, Anchor and chordae in P2 can be seen together with mitral leaflets (also see Video 2). B, Regurgitant flow generated by shortening the ACT from outside the apex as visualized on color Doppler. $A M L$, Anterior mitral leaflet; $P M L$, posterior mitral leaflet.

was shown herein for the mitral leaflets enabling precise chordae positioning and verification of successful deployment.

\section{Limitation}

The in vivo experiments were performed on animals with healthy hearts and, because these were proof-of-concept experiments, we did not attempt to create a mitral prolapse model by cutting the native chordae, as has been done in other published experiments. ${ }^{4}$ These factors could affect how the reported results translate to clinical use and should be investigated in future experiments. In vivo experiments were also limited to placing anchors in the P2 and A2 segments. Although during our experiments, we were able to navigate to all segments, chordal delivery to all segments should be studied in the future.
Because the instrument provides an image of whatever the instrument tip is touching, the operator was confident navigating the instrument from the apex to the mitral valve without the use of ultrasound. Consequently, it was decided to perform implantation using only optical guidance. In reviewing the sequence of implantation experiments, it was observed that the operator became more accurate in anchor placement, but deployment time did not decrease along a learning curve as expected. This is likely because of the limited field of view of the optical finger (8-mm diameter) resulting in significant time spent exploring the leaflet to ensure proper positioning. Future experiments should include the use of ultrasound guidance to expedite positioning on the leaflet.

Finally, the suture length used in our experiments was insufficient to maintain control of the ACT during
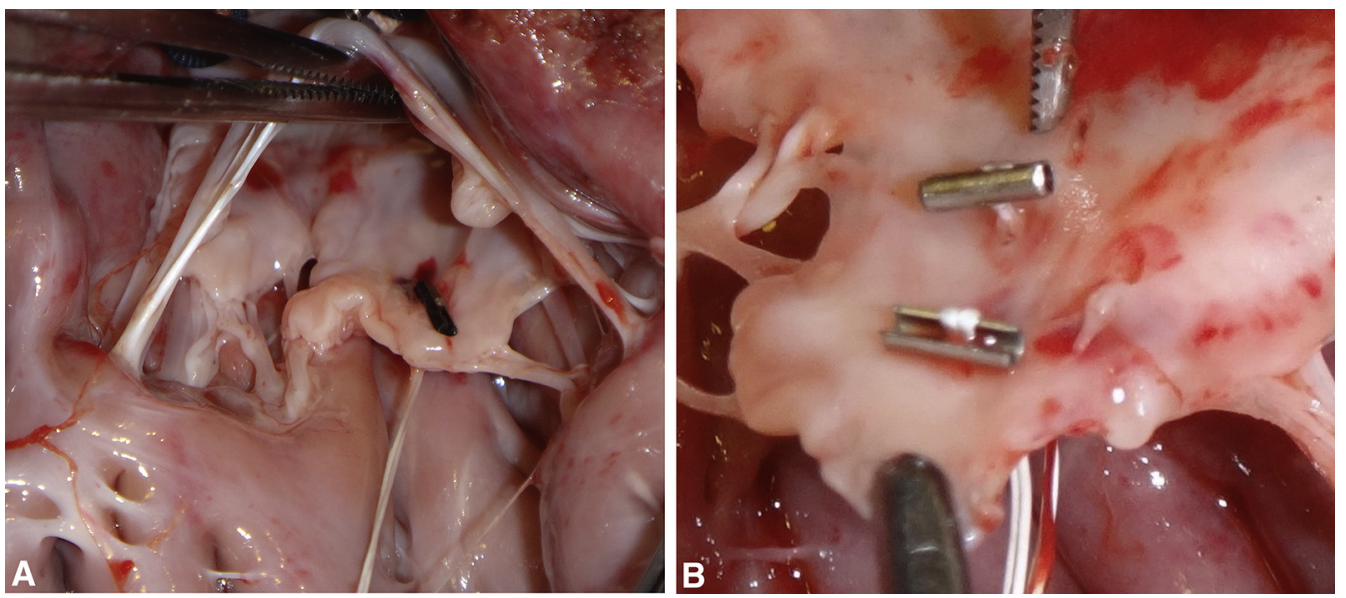

FIGURE 7. Postsurgical views of artificial chordae tendineae placed in the posterior mitral leaflet. A, Single chordae. B, Two chordae. 
instrument removal from the heart. The use of a longer ePTFE suture will eliminate this problem.

\section{CONCLUSIONS}

This study shows how optical imaging can be used to guide the manipulation of valve tissue during off-pump interventions. The camera embedded in the leaflet grasper enables the clinician to visually assess and adjust a potential chordal attachment point on a leaflet to a degree that is not possible with current devices and imaging modalities. Further studies are needed to understand how optical imaging can be integrated more broadly into the workflow of beating-heart interventions.

\section{Conflict of Interest Statement}

One patent application has been filed by Boston Children's Hospital on the overall imaging technology: optically guided surgical devices, US patent $15 / 158,475$ filed 5/18/ 16, PCT/US2016/038147 filed 6/17/16; co-inventors who are also authors are Zurab Machaidze, Margherita Mencattelli, and Pierre Dupont; Boston Children's Hospital has filed a patent application on the chordae replacement technology described in the report. Co-inventors who are also authors are Zurab Machaidze, Karl Price, Gustavo Arnal, and Pierre Dupont. All other authors have nothing to disclose with regard to commercial support.

\section{References}

1. Freed LA, Levy D, Levine RA, Larson MG, Evans JC, Fuller DL, et al. Prevalence and clinical outcome of mitral-valve prolapse. New Engl J Med. 1999; $341: 1-7$.

2. Nishimura RA, Otto CM, Bonow RO, Carabello BA, Erwin JP III, Guyton RA, et al. 2014 AHA/ACC guideline for the management of patients with valvular heart disease: a report of the American College of Cardiology/American Heart Association task force on practice guidelines. J Am Coll Cardiol. 2014;63: e57.

3. Joint Task Force on the Management of Valvular Heart Disease of the European Society of Cardiology (ESC), European Association for Cardio-Thoracic Surgery (EACTS), Vahanian A, Alfieri O, Andreotti F, Antunes MJ, BarónEsquivias G, Baumgartner $\mathrm{H}$, et al. Guidelines on the management of valvular heart disease (version 2012). Eur Heart J. 2012:33:2451-96.

4. Bajona P, Katz WE, Daly RC, Zehr KJ, Speziali G. Beating-heart, off-pump mitral valve repair by implantation of artificial chordae tendineae: an acute in vivo animal study. J Thorac Cardiovasc Surg. 2009;137:188-93.

5. Seeburger J, Leontjev S, Neumuth M, Noack T, Höbartner M, Misfeld M, et al Trans-apical beating-heart implantation of neo-chordae to mitral valve leaflets: results of an acute animal study. Eur J Cardiothorac Surg. 2012;41:173-6.
6. Seeburger J, Rinaldi M, Nielsen S, Salizzoni S, Lange R, Schoenburg M, et al Off-pump transapical implantation of artificial neo-chordae to correct mitral regurgitation: the TACT Trial (Transapical Artificial Chordae Tendinae) proof of concept. J Am Coll Cardiol. 2014;63:914-9.

7. Kiefer P, Meier S, Noack T, Borger MA, Ender J, Hoyer A, et al. Good 5-year durability of transapical beating heart off-pump mitral valve repair with neochordae. Ann Thorac Surg. 2018;106:440-5.

8. Gammie JS, Wilson P, Bartus K, Gackowski A, Hung J, D’Ambra MN, et al. Transapical beating-heart mitral valve repair with an expanded polytetrafluoroethylene chordal implantation device: initial clinical experience. Circulation. 2016;134:189-97.

9. Gammie J, Bartus K, Gackowski A, D’Ambra M, Szymanski P, Bilewska $\mathrm{A}$, et al. Beating-heart mitral valve repair using a novel ePTFE chordal implantation device: a prospective trial. J Am Coll Cardiol. 2018; 71:25-36.

10. Wunderlich NC, Siegel RJ. Peri-interventional echo assessment for the MitraClip procedure. Eur Heart J Cardiovasc Imaging. 2013;14:935-49.

11. Stone G, Lindenfeld J, Abraham W, Kar S, Lim D, Mishell J, et al. Transcatheter mitral-valve repair in patients with heart failure. $N$ Engl J Med. 2018;379: 2307-18.

12. Uchida Y, Tomaru T, Nakamura F, Oshima T, Fujimori Y, Hirose J. Percutaneous fiberoptic cardioscopy of the left ventricle. Jpn Heart J. 1991;32:455-71.

13. Uchida Y. Recent advances in percutaneous cardioscopy. Curr Cardiovasc Imaging Rep. 2011;4:317-27.

14. Vasilyev NV, Martinez JF, Freudenthal FP, Suematsu Y, Marx GR, del Nido PJ Three-dimensional echo and videocardioscopy-guided atrial septal defect closure. Ann Thorac Surg. 2006;82:1322-6.

15. Shiose A, Takaseya T, Fumoto H, Horai T, Kim H, Fukamachi K, et al. Cardioscopy-guided surgery: intracardiac mitral and tricuspid valve repair under direct visualization in the beating heart. J Thorac Cardiovasc Surg. 2011; 142:199-202.

16. Padala M, Jimenez JH, Yoganathan AP, Chin A, Thourani VH. Transapical beating heart cardioscopy technique for off- pump visualization of heart valves. J Thorac Cardiovasc Surg. 2012;144:231-4.

17. Ataollahi A, Berra I, Vasilyev NV, Machaidze Z, Dupont PE. Cardioscopic tooldelivery instrument for beating-heart surgery. IEEE ASME Trans Mechatron. 2016;21:584-90.

18. Rosa B, Machaidze Z, Mencattelli M, Manjila S, Shin B, Price K, et al. Cardioscopically guided beating heart surgery: paravalvular leak repair. Ann Thorac Surg. 2017;104:1074-9.

19. Jensen H, Jensen MO, Waziri F, Honge JL, Sloth E, Fenger-Gron M, et al. Transapical neochord implantation: is tension of artificial chordae tendineae dependent on the insertion site? J Thorac Cardiovasc Surg. 2014; 148:138-43.

20. Nielsen SL, Hansen SB, Nielsen KO, Nygaard H, Paulsen PK, Hasenkam JM. Imbalanced chordal force distribution causes acute ischemic mitral regurgitation: mechanistic insights from chordae tendineae force measurements in pigs. J Thorac Cardiovasc Surg. 2005;129:525-31.

21. Huang J, Triedman J, Vasilyev N, Suematsu Y, Cleveland R, Dupont PE. Imaging artifacts of medical instruments in ultrasound-guided interventions. J Ultrasound Med. 2007;26:1303-22.

22. Ren H, Banani A, Dupont PE. Varying ultrasound power to distinguish surgical instruments and tissue. Med Biol Eng Comput. 2018;56:453-67.

Key Words: mitral prolapse, optical imaging, artificial chordae, transapical 